\title{
Effect of Ethanol Extract of Leaves of Chrysophyllum albidum on the Reproductive Hormones of Lead-Exposed Female Wistar Albino Rats
}

\author{
*OBI, CC; PATRICK-IWUANYANWU, KC; ONYEIKE, EN \\ Department of Biochemistry, Faculty of Science, University of Port Harcourt, Choba, Rivers State, Nigeria; \\ *Corresponding Author Email: Cossyfun@gmail.com
}

\begin{abstract}
This study investigated the ameliorative effect of the ethanol extract of leaves of Chrysophyllum albidum on the ovaries and reproductive hormones of lead-exposed female Wistar albino rats. Lead has no physiological role in the body but exerts many deleterious effects on various organs and systems in humans including the reproductive system; this it achieves mainly by the production of free radicals leading to oxidative stress. A total number of forty-two rats $(160-180 \mathrm{~g})$ were divided into seven groups; group 1 served as the normal control group, group 2 rats were administered $200 \mathrm{mgkg}^{-1}$ of lead and left untreated (negative control group) while groups 3,4,5,6 and 7 were administered lead $\left(200 \mathrm{mgkg}^{-1}\right)$ and 250 , $500,750,1000$ and $1250 \mathrm{mgkg}^{-1}$ body weight of the ethanol extract of the studied plant respectively. All groups received feed and water ad libitum for 30days. A significant $(\mathrm{p} \leq 0.05)$ increase was observed in FSH, LH, estrogen and progesterone levels in $C$. albidum treated groups compared to the negative control group. The histology of the negative control group showed the presence of cysts with no ovarian follicle whereas treated groups showed normal histology of the ovaries with oocytes except for groups 6 and 7.This ameliorative ability of $C$. albidum observed in the present study may be attributed to its high antioxidant properties. Further studies on C. albidum could lead to the development of new and highly affordable drugs for the treatment of female infertility.
\end{abstract}

\section{DOI: https://dx.doi.org/10.4314/jasem.v22i9.23}

Copyright: Copyright (C) 2018 Obi et al. This is an open access article distributed under the Creative Commons Attribution License (CCL), which permits unrestricted use, distribution, and reproduction in any medium, provided the original work is properly cited.

Dates: Received: 28August 2018; Revised: 10September 2018; Accepted: 30 September 2018

Keywords: Chrysophyllum albidum; reproductive hormones; follicle stimulating hormone; progesterone

Reproductive systems are regulated by hormones, and hormonal disorders such as inadequate or excessive production of hormones are the most common causes of infertility. Lead affects the central nervous system as well as hematopoietic, reproductive, hepatic and renal systems and the risk is greater in foetuses and children than in adults as they are still in their developmental stages (Dumitrescu et al., 2015). Rajesh et al. (2015) reported that lead has serious adverse effects on the female reproductive system of mice even at very low doses. Dumitrescu et al. (2015) reported that long term exposure of female rats to low lead levels resulted in structural changes in their ovaries including diffuse oedema, necrosis in the ovarian follicles, optical empty spaces and denudation of the ovarian follicles at various stages of follicle evolution. They concluded that these structural alterations indicate infertility in female rats. Chrysophyllum albidum, a forest fruit tree usually found in tropical Africa and commonly known as African star apple or white star apple, like many medicinal plants in Nigeria has been employed in folklore medicine for the treatment of diseases. Various parts of the plant have been shown to have different therapeutic effects in diseases and health conditions. Study by Jayeoba et al. (2010) showed that
C. albidum contains many minerals with lead $(\mathrm{Pb})$ being totally absent. Chrysophyllum albidum has hypoglycemic and hypolipidemic effects on alloxaninduced diabetic rats as reported by Olorunnisola et al. (2008). Onyeka et al. (2012) reported that the root bark of ethanol extract of $C$. albidum lowered serum testosterone and gonadotrophins concentration. In another study on the ethanol leaf extract of $C$. albidum by Anna et al. (2013), they reported that $C$. albidum decreased hormonal profile but did not suppress spermatogenesis. In this present study, ethanol leaves extract of $C$. albidum was employed to investigate its effect on the reproductive hormones of lead-exposed female wistar albino rats.

\section{MATERIALS AND METHODS}

Procurement of plant materials: The leaves of $C$. albidum were obtained in March, 2016 from Orji Village in Owerri North Local Government Area of Imo State, Nigeria.

Experimental Animals: A total number of fifty-seven matured female Wistar albino rats was used for this study. They were purchased and housed in the Animal House of Pharmacology Department, University of 
Port Harcourt, Choba Campus, Rivers State. The rats weighed between 160 and $180 \mathrm{~g}$. They were allowed to acclimatize for 1 week and were fed normal rat feed (Top feeds- grower's mash) and clean water ad libitum during the acclimatization period and throughout the experimental period. Fifteen of the rats were used for the acute toxicity test to ascertain that the highest dose of the extract used $(1250 \mathrm{mg} / \mathrm{kg})$ was not lethal to the rats using the Limit Test Method described by Walum (1998); while the remaining forty-two rats were used for the study.

Preparation of plant extract: The leaves of C. albidum were rinsed, allowed to dry under room temperature for 3 weeks, then ground into powder using manual home grinder. The extraction was done following the method used by Anna et al. (2013). The ground leaves were soaked in $90 \%$ ethanol for 24 hours, sieved with muslin cloth and filtered using Whatmann No3 filter paper. The extract obtained was allowed to dry completely over a water bath $\left(40^{\circ} \mathrm{C}\right)$, stored in clean dry containers, and kept in the refrigerator until usage. When needed, the extract was dissolved in normal saline $(0.90 \% \mathrm{NaCl})$ at a concentration of $1 \mathrm{~g} / \mathrm{ml}$, and preserved in the refrigerator throughout the study duration.

Experimental design: Forty-two female Wistar albino rats weighing between 160 and $180 \mathrm{~g}$ were divided into seven groups of six rats in each group. The experimental design of Azab et al.(2015) was adopted for the study, and the rats were divided as follows: Group I: Normal Control; received feed and water only ad libitum for 30days.

Group II: Negative Control; received feed, $200 \mathrm{mg} / \mathrm{kg}$ b.w of lead acetate and water ad libitum daily for 30days.

Group III: received feed, $200 \mathrm{mg} / \mathrm{kg}$ b.w of lead acetate, $250 \mathrm{mg} / \mathrm{kg}$ b.w C. albidum ethanol leaf extract and water ad libitum daily for 30days.

Group IV: received feed, $200 \mathrm{mg} / \mathrm{kg}$ b.w of lead acetate, $500 \mathrm{mg} / \mathrm{kg}$ b.wC. albidum ethanol leaf extract and water ad libitum daily for 30days.

Group V: received feed, $200 \mathrm{mg} / \mathrm{kg}$ b.w of lead acetate, $750 \mathrm{mg} / \mathrm{kg}$ b.w C. albidum ethanol leaf extract and water ad libitum daily for 30days.

Group VI: received feed, $200 \mathrm{mg} / \mathrm{kg}$ b.w of lead acetate, $1000 \mathrm{mg} / \mathrm{kg}$ b.w C. albidum ethanol leaf extract and water ad libitum daily for 30days.

Group VII: received feed, $200 \mathrm{mg} / \mathrm{kg}$ b.w of lead acetate, $1250 \mathrm{mg} / \mathrm{kg}$ b.w $C$. albidum ethanol leaf extract and water ad libitum daily for 30days.

Administration of extract was done orally using a cannula for 30days.
Specimen collection: Twenty four hours after the last administration of extract, the rats were anaesthetised using cotton wool soaked in chloroform. The anaesthetised rats were placed on a dissecting slab and the blood samples were collected from the jugular-vein with lithium-heparin bottles for biochemical analysis. The ovaries of the experimental rats were excised, placed in sample holders containing $10 \%$ normal saline and then taken to the laboratory for histopathology examination.

Estimation of Follicle Stimulating Hormone (FSH) concentration: The FSH concentration of the samples were carried out following the method described by Mboso et al., (2013) using AccuBind Enzyme-Linked Immunosorbent Assay (ELISA) Microwells test kits (Monobind Incorporation, USA). The microplate wells were formatted to assay serum reference, control and test specimens in duplicates. A $50 \mu 1$ of the serum reference, control and specimen were pipetted into the assigned wells and $100 \mu \mathrm{l}$ of FSH-Enzyme reagent solution was pipetted into each well. The microplate was gently swirled for $30 \mathrm{sec}$, incubated for $60 \mathrm{~min}$ at room temperature and the contents discarded by decantation. The decant was washed three times with $350 \mu 1$ of wash buffer, then $100 \mu 1$ of the substrate solution was added to the wells, incubated for $15 \mathrm{~min}$ at room temperature and $50 \mu 1$ of stop solution finally added to all the wells and mixed gently for $20 \mathrm{sec}$. The absorbance in each well was read at $450 \mathrm{~nm}$ using a microplate reader. A curve of absorbance for each duplicate serum reference versus the corresponding FSH concentration was plotted and the best-fit curve through the plotted points was drawn. To determine the FSH concentration for the unknown, the average absorbance of the duplicates was located on the vertical axis, the intersecting point on the curve located and the FSH concentration was then read from the horizontal axis of the graph.

Estimation of Luteinizing Hormone (LH) concentration: The LH concentration of the samples were carried out following the method described by Mboso et al., (2013) using AccuBind Enzyme-Linked Immunosorbent Assay (ELISA) Microwells test kits (Monobind Incorporation, USA). The microplate wells were formatted to assay serum reference, control and test specimens in duplicates. A 50 $\mu 1$ of the appropriate serum reference, control and specimen were pipetted into the assigned wells and 100 $\mu$ l of LH-Enzyme reagent solution was also pipetted into the wells. The microplate was gently swirled for $30 \mathrm{sec}$, incubated for $60 \mathrm{~min}$ at room temperature and the contents discarded by decantation. The decant was washed three times with $350 \mu 1$ of wash buffer, then $100 \mu 1$ of the substrate solution was added to all wells, incubated for $15 \mathrm{~min}$ at 
room temperature and $50 \mu 1$ of stop solution finally added to all wells and mixed gently for $20 \mathrm{sec}$. The absorbance in each well was read at 450nm using a microplate reader. A curve of absorbance for each duplicate serum reference versus the corresponding LH concentration was plotted and the best-fit curve through the plotted points was drawn. To determine the LH concentration for the unknown, the average absorbance of the duplicate was located on the vertical axis, the intersecting point on the curve located and the $\mathrm{LH}$ concentration was then read from the horizontal axis of the graph.

Estimation of progesterone concentration: The progesterone concentration of the samples were carried out following the method described by Mboso et al., (2013) using AccuBind Enzyme-Linked Immunosorbent Assay (ELISA) Microwells test kits (Monobind Incorporation, USA). The microplate wells were formatted to assay serum reference, control and test specimens in duplicates. A $25 \mu 1$ of the appropriate serum reference, control and specimen were pipetted into the assigned wells and 50 $\mu$ l of Progesterone Enzyme reagent solution was pipetted into all wells. The microplate was gently swirled for $20 \mathrm{sec}$, incubated for $60 \mathrm{~min}$ at room temperature and the contents discarded by decantation. The decant was washed three times with $350 \mu$ of wash buffer, then $100 \mu 1$ of the substrate solution was added to all wells, incubated for $20 \mathrm{~min}$ at room temperature and $50 \mu \mathrm{l}$ of stop solution finally added to all wells and mixed gently for 20sec. The absorbance in each well was read at $450 \mathrm{~nm}$ using a microplate reader. A curve of absorbance for each duplicate serum reference versus the corresponding progesterone concentration was plotted and the best-fit curve through the plotted points was drawn. To determine the progesterone concentration for the unknown, the average absorbance of the duplicate was located on the vertical axis, the intersecting point on the curve located and the progesterone concentration was then read from the horizontal axis of the graph.

Estimation of estrogen concentration: The estrogen concentration of the samples were carried out following the method described by Mboso et al., (2013) using AccuBind Enzyme-Linked Immunosorbent Assay (ELISA) Microwells test kits (Monobind Incorporation, USA). The microplate wells were formatted to assay serum reference, control and test specimens in duplicates. A $25 \mu 1$ of the appropriate serum reference, control and specimen were pipetted into the assigned wells and $50 \mu 1$ of estradiol (estrogen) biotin reagent was pipetted into all wells. The microplate was gently swirled for $30 \mathrm{sec}$, incubated for $90 \mathrm{~min}$ at room temperature and the contents discarded by decantation. The decant was washed three times with $350 \mu 1$ of wash buffer, then $100 \mu 1$ of the substrate solution was added to all wells, incubated for $20 \mathrm{~min}$ at room temperature and $50 \mu 1$ of stop solution finally added to all wells and mixed gently for $20 \mathrm{sec}$. The absorbance in each well was read at 450nm using a microplate reader. A curve of absorbance for each duplicate serum reference versus the corresponding estrogen concentration was plotted and the best-fit curve through the plotted points was drawn. To determine the estrogen concentration for the unknown, the average absorbance of the duplicate was located on the vertical axis, the intersecting point on the curve located and the estrogen concentration was then read from the horizontal axis of the graph.

Histological examination: Histological examinations were carried out following the method described by Awvioro (2002). The ovaries were excised immediately after the rats were sacrificed and placed in sample holders containing $10 \%$ normal saline. Water was removed from the specimen using graded percentage of alcohol in ascending order from a lower concentration to the absolute, agitation was done using Junior Orbit Shaker and the alcohol from the blocks or sections of tissue were cleared by immersing them in xylene. Thin uniform sections for histological examination were produced using a rotary Microtome. A grease-free slide was placed on a warm plate and was flooded with distilled water. A section was laid on the surface of the slide and every major grease was removed by stretching the surrounding wax carefully with mounted needles. As the water warmed, the section flattened out. The slide was then removed from the hot plate, labelled and dried. The slides were stained using haematoxylin and eosin stains. After staining, the sections were prepared for microscopic examination by mounting them in a suitable medium under a glass cover slip using a mountant. The slides were then viewed under a microscope.

Statistical analysis: All data were subjected to statistical analysis. Values were reported as mean \pm standard error of mean (SEM). The statistical package used was SPSS, while one way ANOVA was used to test for differences between treatment groups. The results were considered significant at p-values of less than 0.05 , that is, at $95 \%$ confidence level $(\mathrm{p} \leq 0.05$

\section{RESULTS AND DISCUSSION}

The results of the female reproductive hormones assayed are shown on Table1. The negative control group showed a significant $(\mathrm{p} \leq 0.05)$ decrease in the concentrations of $\mathrm{FSH}$, progesterone and estrogen compared to the normal control group. Though there was a marked decrease also in the LH concentration of 
the negative control group compared to the normal control, this decrease was not significant $(\mathrm{p} \leq 0.05)$. There were significant $(\mathrm{p} \leq 0.05)$ increase in the FSH, $\mathrm{LH}$, progesterone and estrogen concentrations of $C$. albidum treated groups compared to the negative control group in a dose-dependent manner up till group5 $(750 \mathrm{mg} / \mathrm{kg} \quad$ B.W extract) except for progesterone where group7 had the highest value. Among the $C$. albidum treated groups, significant $(p \leq 0.05)$ increase in the FSH concentration of group5 compared to groups 3,6 and 7 ; significant $(p \leq 0.05)$ increases in LH concentrations of groups 5 and 6 compared to group 3 , and significant $(\mathrm{p} \leq 0.05)$ decrease in $\mathrm{LH}$ concentration group 7 compared to groups 5 and
6 were observed.Group7 showed a significant $(\mathrm{p} \leq 0.05)$ increase in progesterone concentration compared to group6; while the estrogen concentration of group5 significantly $(\mathrm{p} \leq 0.05)$ increased compared to groups 3,6 and 7 .

The results of the histological examination of ovaries of the control and test rats are presented in Plates 1 to 7. The histology of the negative control group showed the presence of cysts with no ovarian follicle but treatment with $C$. albidum returned the ovaries to their normal histological states and restored the production of ovarian follicles. There was absence of oocytes in groups 6 and 7 .

Table 1: Serum female reproductive hormone concentrations of the experimental rats

\begin{tabular}{lllll}
\hline GROUPS & FSH $(\mathrm{mlu} / \mathrm{ml})$ & LH $(\mathrm{mlu} / \mathrm{ml})$ & Prog. $(\mathrm{ng} / \mathrm{ml})$ & Estro. $(\mathrm{pg} / \mathrm{ml})$ \\
\hline Group 1 & $2.47 \pm 0.09^{\mathrm{b}}$ & $2.23 \pm 0.30$ & $27.20 \pm 0.80^{\mathrm{b}}$ & $64.33 \pm 4.18^{\mathrm{b}}$ \\
Group 2 & $1.53 \pm 0.22^{\mathrm{a}}$ & $1.30 \pm 0.15$ & $16.67 \pm 1.16^{\mathrm{a}}$ & $42.00 \pm 1.15^{\mathrm{a}}$ \\
Group 3 & $2.13 \pm 0.15^{\mathrm{x}}$ & $3.00 \pm 0.06^{\mathrm{b}, \mathrm{x}}$ & $31.13 \pm 2.55^{\mathrm{b}}$ & $43.33 \pm 1.76^{\mathrm{a}, \mathrm{x}}$ \\
Group 4 & $2.47 \pm 0.19^{\mathrm{b}}$ & $3.40 \pm 0.12^{\mathrm{a}, \mathrm{b}}$ & $28.07 \pm 1.33^{\mathrm{b}}$ & $53.00 \pm 4.51$ \\
Group 5 & $2.87 \pm 0.09^{\mathrm{b}, \mathrm{c}}$ & $4.13 \pm 0.32^{\mathrm{a}, \mathrm{b}, \mathrm{c}}$ & $30.60 \pm 1.25^{\mathrm{b}}$ & $62.00 \pm 1.53^{\mathrm{b}, \mathrm{c}}$ \\
Group 6 & $2.00 \pm 0.10^{\mathrm{x}}$ & $3.83 \pm 0.09^{\mathrm{a}, \mathrm{b}, \mathrm{c}}$ & $27.57 \pm 1.23^{\mathrm{b}, \mathrm{c}}$ & $41.00 \pm 3.79^{\mathrm{a}, \mathrm{x}}$ \\
Group 7 & $1.83 \pm 0.09^{\mathrm{c}}$ & $2.50 \pm 0.17^{\mathrm{b}, \mathrm{x}}$ & $36.67 \pm 3.32^{\mathrm{a}, \mathrm{b}, \mathrm{x}}$ & $38.67 \pm 5.70^{\mathrm{a}, \mathrm{x}}$ \\
\hline
\end{tabular}

Values are expressed as mean \pm SEM; $n=6$; Statistical package used is SPSS. Key: Group 1= Normal control; Group $2=$ Negative control; Group 3= Treated with 250mg/kg Extract; Group 4= Treated with 500mg/kg Extract; Group 5= Treated with 750mg/kg Extract; Group 6= Treated with 1,000mg/kg Extract; Group 7 = Treated with 1,250mg/kg Extract.

Values with superscript " $a$ " are significantly different from the normal control, Group $1,(p<0.05)$

Values with superscript " $b$ " are significantly different from the negative control, Group2, $(p<0.05)$

Values without superscript " $a$ " and " $b$ " are not significantly different from groups 1 and $2,(p>0.05)$

Values with superscript " $c$ " are significantly different from values with superscript " $x$ " across the treated groups, ( $p<0.05)$

Values with superscript " $x$ " are not significantly different from each other across the treated groups, $(p>0.05)$

The findings in this present study corroborate that of Ayinde et al., (2012) who observed a non-significant $(\mathrm{p} \leq 0.05)$ decrease in $\mathrm{LH}$ and a significant $(\mathrm{p} \leq 0.05)$ decrease in FSH concentrations in lead-exposed rats compared to the control group. Waseem and Rehman (2015) reported significant $(\mathrm{p} \leq 0.05)$ reduction in progesterone and estrogen concentrations in leadexposed mice compared to the control group. A contrary result in progesterone level was reported by Nakade et al., (2015) who observed no significant $(\mathrm{p} \leq 0.05)$ change in the progesterone level of rats treated with different concentrations of lead compared to the control group. The histological study of the ovaries in this study revealed that lead induced ovarian cysts in the ovaries of the negative control rats with no formation of oocytes.

However, the treated groups showed that the leadinduced abnormalities in the ovaries were mitigated by C. albidum leaves extract, though the highest doses (1000 and $1250 \mathrm{mg} / \mathrm{kg}$ b.w) showed evidences of toxicity as no oocyte was seen indicating possible maturation arrest. The group treated with $750 \mathrm{mg} / \mathrm{kg}$ b.w (group5) C. albidum leaves extract had the most ameliorative effect on the reproductive system.

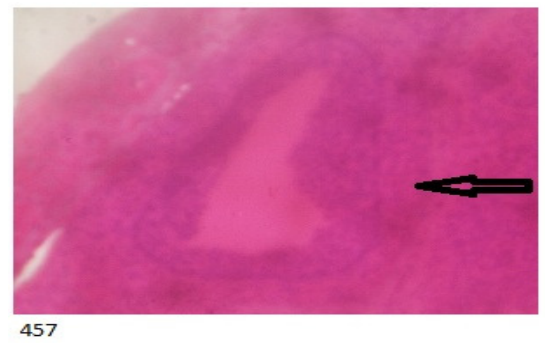

Plate1:Ovary histology of group 1 (Normal control rats).H\&E X200.Micrograph of ovary showing corpus luteum (arrowed structure). This implies that this ovary has been able to produce a mature ovarian follicle which led to production of an ovum at the time of ovulation.

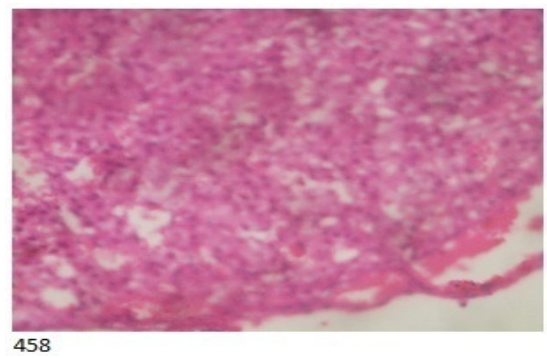

Plate2:Ovary histology of group 2 (Negative control rats),H\&E X200.Micrograph of ovary showing the cortical area of the ovary

OBI, CC; PATRICK-IWUANYANWU, KC; ONYEIKE, EN 
without any ovarian follicle. Some cysts are seen which represents distortion of ovarian histology.

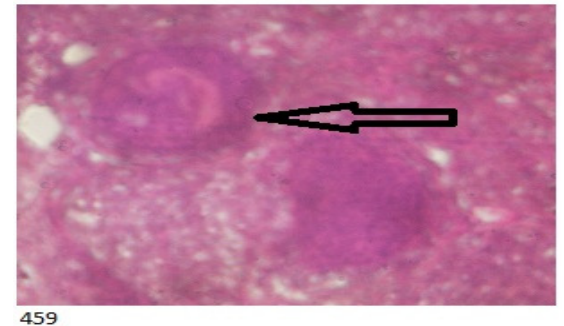

Plate3 Ovary histology of group 3 (Treated rats- $250 \mathrm{mg} / \mathrm{kg}$ b.w extract)H\&E X200. Micrograph of ovarian tissue showing the cortical region. Some ovarian follicles were seen. The arrowed follicle is a secondary ovarian follicle. This ovary reveals normal histologic features.

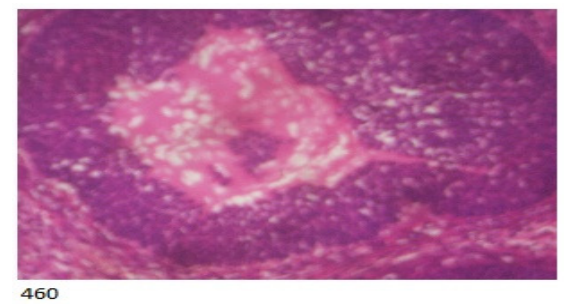

Plate4:Ovary histology of group 4 (Treated rats- $500 \mathrm{mg} / \mathrm{kg}$ b.w extract)H\&E X200.Micrograph of ovarian follicle showing a primary oocyte with normal histological features.

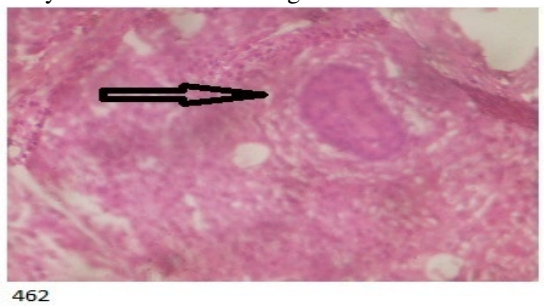

Plate5: Ovary histology of group 5 (Treated rats- $750 \mathrm{mg} / \mathrm{kg}$ b.w extract)H\&E X200.Micrograph of ovarian tissue showing corpus luteum. This is a normal finding in the histology of the ovary.

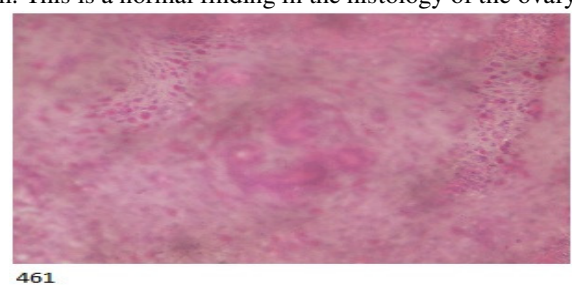

Plate6:Ovary histology of group 6 (Treated rats- $1000 \mathrm{mg} / \mathrm{kg} \mathrm{b.w}$ extract).H\&E X200.Micrograph of ovarian tissue with no oocytes seen. It is possible that there was maturation arrest.

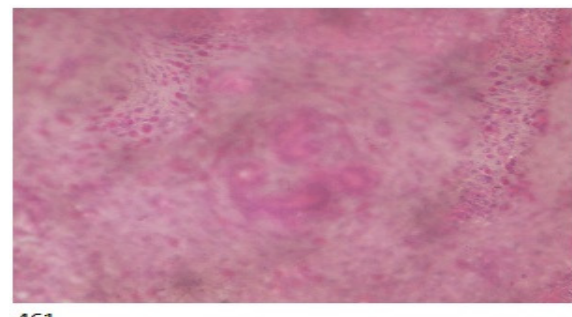

461
Plate7: Ovary histology of group 7 (Treated rats- $1250 \mathrm{mg} / \mathrm{kg} \mathrm{b.w}$ extract).H\&E X200.Micrograph of ovarian tissue without any oocytes seen. It is possible that there was maturation arrest.

The results of the reproductive hormonal assays of the negative control group compared to the normal control group suggest that serum levels of FSH, LH, estrogen and progesterone were suppressed by treatment with lead. Treatment with $C$. albidum however conferred ameliorative effects on the experimental rats as observed by the increases in FSH, LH and estrogen concentrations among treated groups in a dosedependent manner up till group 5. Although significant increases in progesterone concentrations were observed among treated groups compared to the negative control group, these increases were not dosedependent. Suppression of female reproductive hormones has been shown to cause alteration and subsequent seizure of the estrous cycle (known as amenorrhoea) of female rats at diestrous stage. Estrous cycle is the reproductive cycle which takes place in sexually matured female animals and gives an indication of the functionality of the ovary and uterus (Kumar et al., 1997; Ugwoke et al., 2005; Andersson et al., 2013; Rajesh et al., 2015). This hormonal suppression observed in the present study can be attributed to lead-induced stress which causes the hypothalamus to release glucocorticoid hormones in response to the stress. Continuous increase in serum glucocorticoid concentration leads to production of free radicals, and also decline in the concentration of GnRH leading to reduced synthesis and secretion of LH and FSH. Progesterone is produced majorly by the corpus luteum whose formation is triggered by a surge of LH; hence significant decrease in the progesterone level of the negative control group compared to the normal control group in this present study can be attributed to the reduced synthesis of LH. Estrogen has antioxidant properties, but with suppressed generation of FSH and elevation of glucocorticoids, its synthesis and secretion is highly reduced. This leads to excessive oxidative stress which can subdue or hinder folliculogenesis and the entire estrous cycle (Sapolsky et al., 2000; Nepomnaschy et al., 2004; Chatterjee and Chatterjee, 2009). Treatment with $C$. albidum was able to confer protection against lead-induced toxicity as evidenced in the significant $(\mathrm{p} \leq 0.05)$ increases in FSH, $\mathrm{LH}$, progesterone and estrogen in a dose-dependent manner up till the group treated with $750 \mathrm{mg} / \mathrm{kg}$ b.w. of the extract. This positive effect on the reproductive hormones observed in this study can be attributed to $C$. albidum's reactive oxygen species scavenging ability since it is rich in antioxidants. Phytochemical analysis of $C$. albidum showed that it contains vitamin $\mathrm{C}$, vitamin $\mathrm{E}$, vitamin $\mathrm{A}$, selenium, iron, copper, zinc, manganese, and a lot of other vitamins, minerals and alkaloids. Its vitamin $\mathrm{C}$ content was found to be 100 
times that of oranges and 10 times that of guava and cashew (Amusa et al., 2003; Jayeoba et al., 2010; Thomas and Olufunke, 2012). Vitamin A can quench $\mathrm{O}_{2}$, prevent and stop lipid peroxidation; on the other hand, vitamin $\mathrm{C}$ can eliminate peroxyl radicals in the aqueous phase of cells hence inhibiting peroxidation initiation. Furthermore, vitamin $\mathrm{C}$ reduces circulating glucocorticoids produced during stress (Rifici and Khachadurian, 1993); hence reduction in serum glucocorticoids increases the secretion of GnRH by the hypothalamus while vitamin E neutralizes free radicals thereby preventing lipid oxidation inside membranes (McDowell, 2000; McDowell et al., 2007). With increased serum GnRH concentration, syntheses and secretions of LH, FSH (and subsequently estrogen and progesterone) are also elevated. This eventually restores the folliculogenesis and estrous cycle back to normal (Sapolsky et al., 2000; Nepomnaschy et al., 2004; Chatterjee and Chatterjee, 2009). However, except for progesterone assay where the highest concentration was observed in group7 rats; FSH, LH and estrogen assays revealed significant decreases in the concentrations of groups 6 and 7 (1000 and 1250 $\mathrm{mg} / \mathrm{kg} \mathrm{b.w)} \mathrm{compared} \mathrm{to} \mathrm{group5} \mathrm{(750mg/kg} \mathrm{b.w).}$ Absence of oocytes, suggesting possible maturation arrest were equally observed from the histology of groups 6 and 7 rats. These observations could suggest that $C$. albidum possibly has toxic effects on the reproductive hormones and ovaries of the experimental rats at concentrations of $1000 \mathrm{mg} / \mathrm{kg} \mathrm{B.W}$ and above.

The elevation in female hormonal levels in this present study probably explains why in the Eastern part of Nigeria, C. albidum is linked to female fertility and as such used as one of the ingredients in preparing herbal medicines for women trying to conceive. Also pregnant women are often seen eating (and advised to eat) the fruits especially in the early stage of pregnancy; and even cutting down $C$. albidum trees was forbidden in the olden days.

Conclusion: Based on findings in this study, it can be concluded that $C$. albidum effectively ameliorated the deleterious effects of lead on the reproductive hormones and ovaries of experimental rats especially at the concentration of $750 \mathrm{mg} / \mathrm{kg}$ b.w. This study has therefore been able to establish that $C$. albidum can be employed in the treatment of female infertility; and lead toxicity. Further investigations should be carried out to ascertain the actual active agent that conferred this protection and to possibly develop easily available drugs that can boost fertility in females.

\section{REFERENCES}

Amusa, NA; Ashaye, OA; Oladapo, MO (2003). Biodeterioration of the African star apple
(Chrysophylum albidum) in storage and the effect on its food value. Afr. J. Biotech. 2(3): 56-59.

Andersson, H; Rehm, S; Stanislaus, D; Wood, CE (2013). Scientific and Regulatory Policy Committee (SRPC) Paper Assessment of Circulating Hormones in Nonclinical Toxicity Studies III. Female Reproductive Hormones. $J$. Toxicol. Pathol. 41(6): 921-934.

Anna, OC; Oladapo, FO; Ugochukwu, AA; Chikere, OU; Bankole, L; Anthony, AO (2013). Ethanol Leaf Extract of Chrysophyllum albidum on sperm analysis, hormonal profile, SOD and testicular histology of adult male wistar rats. Agric. Biol. J.North Am. 4(3): 160-165.

Awvioro, OG (2002). Histochemistry and Tissue Pathology. Principles and Techniques. ISBN, 978356279, 154-162.

Ayinde, OC; Ogunnowo, S; Ogedegbe, RA (2012). Influence of Vitamin $\mathrm{C}$ and Vitamin $\mathrm{E}$ on testicular zinc content and testicular toxicity in lead exposed albino rats. BMC Pharmacol. Toxicol. 13(17): 1-8.

Azab, AE; El-Dakhly, AT; Qutaiba, K; Alrawi; Mohamed, OA (2015). Protective Effects of Sesame Oil Against Lead Acetate Induced Haemato-Biochemical Toxicity in Albino Mice. Int. J. Sci.Res. 4(2): 2053-2063.

Chatterjee, A; Chatterjee, R (2009). How stress affects female reproduction: An overview. Biomed. Res. 20(2): 79-83.

Dumitrescu, E; Chiurciu, V; Muselin, F; Popescu, R; Brezovan, D (2015). Effects of long-term exposure of female rats to low levels of lead: ovary and uterus histological architecture changes. Turk. J. Biol. 39(2): 284-289.

Jayeoba, OJ; Ige, MM; Omolaiye, JA; Gbadamosi, SO; Ogunbanjo, RO; Abiola, IO (2010). Chemical composition and physical properties of African star apple (Chrysophyllum albidum). ASSET: An Int. J. (Series A). 7(1): 37-42.

Kumar, TR; Wang, Y; Lu, N; Matzuk, MM (1997). Follicle stimulating hormone is required for ovarian follicle maturation but not male fertility. Nat. Genet. 15(2): 201-204.

Mboso, OE; Eyong, EU; Ebong, PE; Iwara, A; Odey, M (2013). The effects of the ethanolic extract of Ereromastax speciosa leaf on the serum levels of 
luteinizing hormone, follicle stimulating hormone, progesterone and estradiol in female pubertal rats. Ann. Biol. Res. 4(2), 136-40.

McDowell, LR (2000). Vitamins in Animal and Human Nutrition.2nd edIowa State University Press. Ames, IA.

McDowell, LR; Wilkinson, N; Madison, R; Felix, T (2007).Vitamins and minerals functioning as antioxidants with supplementation considerations. In: Florida Ruminant Nutrition Symposium. Best Western Gateway Grand, Gainesville, FL (Pp. 3031).

Nakade, UP; Garg, SK; Sharma, A; Choudhury, S; Yadav, RS; Gupta, K; Sood, N (2015).Leadinduced adverse effects on the reproductive system of rats with particular reference to histopathological changes in uterus. Indian J.Pharm. 47(1): 22.

Nepomnaschy, PA; Welch, K; McConnell, D; Strassmann, BI; England, BG (2004). Stress and female reproductive function: a study of daily variations in cortisol, gonadotrophins, and gonadal steroids in a rural Mayan population. Am. J. Hum. Biol. 16(5): 523-532.

Olorunnisola, DS Amao, I. S., Ehigie, D. O. Ajayi, Z. A. F (2008). Antihyperglycemic and hypolipidemic effect of ethanolic extract of Chrysophyllum albidum seed cotyledon in alloxan induced diabetic rats. Res. J. Appl. Sci. 3(2): 123127.

Onyeka, AC; Aligwekwe, AU; Nwakanma, AA; Bakare, AA; Ofoego, UC (2012). Effects of Ethanolic Root Bark Extract of Chrysophyllum albidum on Serum Superoxide Dismutase, Catalase and Malondialdehyde in Rat. Int. J. Pharm. Sci. Res. 3(3): 347-350.
Rajesh, K; Debnath, R; Verma, R (2015).Adverse effects of lead acetate on female reproductive system of mice. World J. Environ. Biosci. 4(2):4249

Rifici, VA; Khachadurian, AK (1993). Dietary supplementation with vitamins $C$ and $E$ inhibits in vitro oxidation of lipoproteins. J. Am. Coll. Nutr. 12(6): 631-637.

Sapolsky, RM; Romero, LM; Munck, AU (2000). How do glucocorticoids influence stress responses? Integrating permissive, suppressive, stimulatory, and preparative actions. Endocr. Rev. 21(1): 55-89.

Thomas, O; Olufunke, P (2012).Nutrient composition and micronutrient potential of three wildly grown varieties of African star apple (Chrysophyllum albidum) from Nigeria. Afr. J. Food Sci. 6(12): 344-351.

Ugwoke, CC; Nwobodo, ED; Unekwe, P; Odike, M; Chukwuma, ST; Amilo, G (2005). The reproductive dysfunction effects of gasoline inhalation in albino rats. Niger. J. Physiol. Sci. 20(1): 54-57.

Walum, E (1998). Acute oral toxicity. Environ.Health Perspect. 106 (Suppl 2): 497-503.

Waseem, N; Rehman, S (2015). The Efficiency of Garlic Extract in Prevention of Lead Acetate Toxicity on Fallopian Tube-A Hormonal Study. Biol. Med. 7(1):227. 